\title{
Quality of Life Considerations in 'Caregiver' Renal Donors in Countries with High Living Donor Ratios: A Narrative Review
}

\author{
Agarwal N, Rana AKS, Goyal H, Kumar S, Dokania MK* \\ Department of Surgery, Renal Transplant Unit, Postgraduate Institute of Medical Education and Research (PGIMER), India
}

Submission: April 18, 2018; Published: May 03, 2018

*Corresponding author: Dr. Manoj kumar dokania, Room No. 304, Postgraduate Institute of Medical Education and Research (PGIMER) and Dr. Ram Manohar Lohia Hospital (RMLH), Delhi 110001, India, Email: dr_manojdokania@yahoo.com

\begin{abstract}
Introduction: Chronic Kidney disease (CKD) is a major cause of mortality and morbidity in the world today, including in India. Transplantation has been proven to be the best form of renal replacement therapy (RRT) terms of quality of life and longevity for end-stage renal disease (ESRD). In India, the annual requirement of renal transplants is more than 200,000, of which only about 6000 are performed. Other problems specific to developing countries like India are the poor ratio of deceased donor to live donor renal transplants ( $<1: 10)$, poor infrastructure, and, sociocultural factors. Live donation follows a specific pattern; a high female: male donor ratio (>8:1), and, blood relatives (parents, grandparents, siblings) and/or spouses (mainly wives) as the main donors. The governing laws are cognizant of this trend.

Quality of life of 'caregiver' donors: Key financial, emotional and physical support is provided by Family donors, essentially 'caregiver donors', viz, they are associated with the intimate care and treatment of the CKD patient. They thus work as nonprofessional health care providers, without regard to their own long-term health and well-being. Many authors feel that long-term psychological and mental health outcomes in living donors may be consequent to pre-operative and postoperative variables like pre-existing anxiety or recipient complications. Support interventions may improve caregivers' quality of life and mental health. These informal caregivers can also experience stress, nihilism, depression, lack of confidence and poor quality of life. However, their needs are never discussed or prioritized at any forum or adequately in literature. We have recently designed a prospective study for this purpose; this review aims to sensitize the readers to this unique subgroup.

Keywords: Quality of life; Caregiver donor; Live donor renal transplant; Developing countries India
\end{abstract}

Abbreviations: CKD: Chronic Kidney Disease; ESRD: End-Stage Renal Disease; DM: Diabetes Mellitus; HT: Hypertension; LRRT: Live Related Renal Transplantation; RRT: Renal Replacement Therapy

\section{Introduction}

Chronic Kidney disease (CKD) is a major cause of mortality and morbidity in the world today. Due to the unusually high prevalence of diabetes mellitus (DM) and hypertension (HT) in the Indian population, we are in the midst of an epidemic of CKD. CKD, when changes to end-stage renal disease (ESRD), requires renal replacement therapy (RRT) either as dialysis or renal transplant. Transplantation has been proven to be the best form of replacement therapy in terms of quality of life and longevity [1].

In India, the annual requirement of renal transplants is more than 200,000 , of which only about 6000 are able to be performed [2]. More than half of the remainders die while awaiting transplant; the situation is compounded by poor infrastructure, especially with respect to dialysis machines and personnel, and in public hospitals catering to the low socioeconomic groups. Another problem specific to developing countries like India is the poor ratio of deceased donor to live donor renal transplants $(<1: 10)$, notwithstanding the absolute annual numbers of live donor renal transplants in India every year $(\sim 6000)$, which rival those in leading countries like the USA. The standard has been set by countries like Spain and the Netherlands where almost $98 \%$ of renal transplants are after deceased donation. Sociocultural factors like fear, religious practices, ignorance are barriers to deceased organ donation [3].

Live donation in India follows a specific pattern; blood relatives (parents, grandparents, siblings) or spouses (mainly wives) are the main donors. The ratio of female: male donors is also high (>8:1). Ingrained cultural practices like close family bonds and joint families encourage this trend. The government, seeing the behavioral pattern in society, kept these norms in mind while formulating The Transplantation of Human Organs Act, 1994, along with its subsequent modifications [2]. 
Live related renal transplantation (LRRT, including spousal donors) provides key financial, emotional and physical support. Family donors in India are essentially 'caregiver donors', viz, they are associated with the intimate care and treatment of the CKD patient right from the time of diagnosis and beyond. An informal caregiver may be a close friend or family member (including partner or spouse) who takes care of a dependant person. In the context of CKD, caregiver responsibilities include dialysis support (cost, transport of the recipient periodically for dialysis, or, performance of dialysis at home), providing drugs and nutrition, nursing care and medical appointments. They hence function as nonprofessional health care providers. Thus, they share the financial, emotional and physical burden of the disease as well [4]. When caregivers become donors, an additional issue arises viz., of their own long-term health and well-being. While it is established that unilateral nephrectomy is safe for the donor in the long run with respect to maintenance in glomerular filtration rate (GFR), hypertension and heart disease $[5,6]$, the psychosocial and quality of life impact is less wellknown [7-9]. Many authors feel that long-term psychological and mental health outcomes in living donors may be consequent to pre-operative and postoperative variables like pre-existing anxiety or recipient complications; these need to be studied in greater detail. Unfortunately, attention to the needs and education of caregiver donors is lacking in literature. Support interventions may improve caregivers' quality of life and mental health, thereby improving medical and psychosocial outcomes for the recipient.

\section{Effect of Renal Transplant on Mental and Physical Health of Donor}

\section{Mental health}

Many studies shows that a minority of living kidney donors (5-20\%) experience suboptimal psychological outcome after living kidney donation [6]. Various studies highlight the influence of complication among donors and recipients on donor's mental health, but the results are mixed. Two studies show that donors who had a longer recovery period or complications after donation had a lower score on the mental component of quality of life post donation.

Jacobs et al. [10] found in their study that out of 2455 kidneys donors, 95\% rated their experience was good to excellent and $9 \%$ reported that fair or poor overall donor experience, financial burden, regret or discomfort with decision to donate, or psychological difficulties since donation. These poor outcomes were mainly associated with recipient graft failure. Financial burden was mainly associated with donor's lower education level [10].

Minz et al. [11] also found in 2003 in 75 donors that there were no major depressive or anxiety disorders following donation. No donor regretted the decision to donate, and $96 \%$ were willing to encourage organ donation. As expected, adverse physical factors like prolonged donor hospitalization, persistent pain, poor recipient reciprocation, or recipient death were associated with a poor psychosocial outcome [11]. Contrary to these results, two other studies did not find a relationship between the occurrence of medical complications and psychological outcome after postdonation.

Mixed results were also found on the relationship between medical complication among recipients and donors mental health post-donation. While various studies found no association between recipients' medical complications and donors' quality of life.

Giessing et al. [12] also found an association between unfavorable recipient outcomes and lower quality of life among donors. The contradictory findings might be partly explained by the different aspects of mental health that were measured in the studies, for instance measuring quality of life is not the same as measuring psychological symptoms [12].

Keyes et al. [13] stipulate the importance of both positive and negative aspects of mental health defined as wellbeing and psychological symptoms respectively. Wellbeing consists of factor such as satisfaction with life, personal growth and social contribution. Psychological symptoms consist of factors such as depressive mood and cognitive problems [13].

It has been seen that kidney donors usually experience psychosocial benefits, including improved self-esteem and improved donor-recipient relationships [14]. Most also report no regrets $[9,15]$ and would donate again [10]. The reasons for poor psychological outcomes in living donors are pre-donation ambivalence, compromised mental health, strained relationship with the recipient, lack of financial resources, and pressure regarding donation $[11,16]$.

In another study, Tong et al. [17] found that kidney donors underwent a profound change; and were required to renegotiate their identity, roles, and relationships. The authors recommend strategies to protect against unwarranted coercion, and to maximize donor resilience, capacity to negotiate their multiple roles as a patient and care, emotional fortitude, and ability to have balanced expectations and relationships with the recipient and the family to ensure the long-term well-being of donors [17]. All the studies emphasize the delicate role of donor in the context of the recipient being part of the family.

\section{Impact of renal donation on physical health}

Renal transplant also affects the physical health of renal donor. The main components of physical change would be expected in blood pressure, GFR, appearance of proteinuria, and, in worst situations, renal failure. A cross-sectional study was conducted at University Hospital of Yopougon in Abidjan that focused on 29 living kidney donors. Only 14 living kidney donors were included; 3 complained residual pain and 5 living kidney donors had regular nephrological follow up. Significant 
proteinuria was noted in $7 \mathrm{LKD}$, and $6 \mathrm{LKD}$ had GFR $<60 \mathrm{~mL} / \mathrm{min}$ [18].

Fehrman-Ekholm et al. found significant proteinuria $>1 \mathrm{~g} / 24 \mathrm{~h}$ in $3 \%$ of LKD. Proteinuria was associated with hypertension and reduction of GFR $[19,20]$.

Ibrahim et al. [21] found in their study that the age at donation was associated with the development of albuminuria. The many published studies reports a lower risk of kidney failure among LKD and little difference from the risk in the general population $[19,20]$. This risk of ESRD is estimated at less than that of the general population [21] although a recent study showed the opposite with a risk of 11.38 times higher compared to the general population [22].

In one of the few Indian studies on the subject by Sahay et al. [23], 50 donors who had nephrectomy between 3 months and 20years previously were assessed for physical morbidity (hypertension, azotaemia), mortality and psychological outcomes. They found that there was a decrease in GFR and increase in renal length, with some proteinuria and rise in blood pressure. They have advised larger studies on the subject with the initiation of a donor registry in the country [23].

Benzing et al. [24] retrospectively evaluated 72 donors who had undergone nephrectomy over 12 years at their institution, using the SF-36 and special LKD questionnaires. They found no change in systolic or diastolic blood pressure, mild proteinuria in 6 patients, and a higher QoL index than the general population [24].

\section{Quality of life of recipients}

Individuals with kidney failure are often selected for kidney transplantation because the quality of life and return to normal life is far better than life on haemodialysis. Therefore, assessment of quality of life is important; there are many validated instruments for this. The health-related quality of life (HRQOL) of transplant recipients can be general HRQOL instruments such as the 36-item short-form health survey (SF-36) and transplantspecific surveys such as the Kidney Transplant Questionnaire (KDQOL-36). In general, HRQOL assessments improve with transplantation in functional and physical domain [25].

Sleep disorders are common and multi-factorial in patients with advanced chronic kidney disease and end-stage renal disease (ESRD). Sleep disorders and disturbances have a negative impact on wellbeing and quality of life. Many studies show that sleep disturbances, sleep apnoea and restless legs syndrome, all tend to improve after haemodialysis or renal transplant [26].

People who receive a kidney transplant experience overall better quality of life (QOL) than those on dialysis. However, one area of QOL that does not seem to improve after transplant is sexuality. Several factors may affect post-transplant sexuality and sexual functioning including chronic illnesses, pre transplant dialysis and medication side effects. In addition, there may be pre-existent problems in sexual functioning by up to $50 \%$. These expectedly negatively affect QOL and life satisfaction [27].

Pruritus also has a negative impact on quality of life (QoL) in dialysis patients. If pruritus was evaluated objectively using the Visual Analogue Scale (VAS), the Visual Rating Scale (VRS), and the Numerical Rating Scale (NRS), it was found that prevalence of pruritus markedly reduces after renal transplantation but remains substantially higher than in the general population and impacts upon quality of life in these patients [28].

\section{Importance of caregivers in CKD}

In a chronic and morbid condition like CKD, the burden on the family is considerable. The patient is unable to negotiate the stress of treatment, illness, planning and travelling on his own. Even with the assistance of professional healthcare providers and government and non-government agencies, the role of professional healthcare providers such as family and friends, is very important. These informal caregivers can also experience stress, nihilism, depression, lack of confidence and poor quality of life. However, their needs are never discussed or prioritized at any forum or adequately in literature [4]. In a study by Baek et al., the parents of 79 children receiving dialysis or transplant were administered a special questionnaire (Family Impact Module), and it was found that scores were worse for haemodialy sis, as compared to peritoneal dialysis or transplant [29]. In another study from Brazil by Garcia et al, 50 donors were asked to respond to the SF-36 questionnaire before and after transplantation. Most donors reported positive outcomes, about psychological well-being and wishing to donate again. The results were particularly positive in donors closely related to the recipient [30]. Such studies should improve our understanding of "care" of caregivers.

\section{Instruments for measurement}

The WHO definition of quality of life is "Quality of life is defined as individuals' perceptions of their position in life in the context of the culture and value systems in which they live and in relation to their goals, expectations, standards and concerns". The WHOQOL-100 questionnaire is an instrument developed to measure the generic health-related quality of life. It has been validated in many countries and languages, and has been in use since 1997. As the name suggests, it has 100 items and may be too lengthy for practical use. Hence, a brief equated version, the WHOQOL BREF with 26 items across four domains is widely used. The recognition of the multi-dimensional nature of quality of life is reflected in the WHOQOL-100 structure. These are scored on an ordinal scale and equated with the WHOQOL 100 mathematically for better reproducibility. The WHOQOL BREF (Dialysis) is a 32-item Health-Related Quality of Life Questionnaire (HRQOL) which has been modified for use from WHOQOL BREF, with 4-dialysis specific items. It is useful in CKD patients on dialysis, as well as transplant recipients. 
Hospital Anxiety and Depression Scale (HADS) was developed by Zigmond and Snaith in 1983. It is a common and simple screening tool used by psychiatrists and other clinicians to identify underlying anxiety and depression in patients or normal individuals. It has 14 items and generates ordinal data [31]. In our tertiary care hospital, about 50 transplants are performed each year, mostly LRRT. Since ours is a government hospital, there are no operation or inpatient charges; however, the life-long postoperative immunosuppressive medication is prohibitively expensive for a large number of patients from a weak socioeconomic background. This is a factor for noncompliance and graft failure in some cases. As mentioned earlier, since most of the donors are caregivers, the medical, emotional and financial stress is shared by the entire family. There are no studies from India assessing the quality of life following transplant for this unique group. We have recently designed a prospective study for this purpose; this review aims to sensitize the readers to this unique subgroup.

\section{References}

1. Trivedi H, Vanikar A, Patel H, Kanodia K, Kute V, et al. (2016) High prevalence of chronic kidney disease in a semi-urban population of Western India. Clin Kidney J 79(3): 438-443.

2. Organ Donation and Transplantation Awareness in Chennai and Tamil Nadu.

3. NOTTO: National Organ \& Tissue Transplant Organization.

4. Tong A, Sainsbury P, Craig JC (2008) Support interventions for caregivers of people with chronic kidney disease: a systematic review. Nephrol Dial Transplant 23(12): 3960-3965.

5. von Zur-Mühlen B, Berglund D, Yamamoto S, Wadström J (2014) Single-centre long-term follow-up of live kidney donors demonstrates preserved kidney function but the necessity of a structured lifelong follow-up. Ups J Med Sci 119(3): 236-241.

6. Morgan BR, Ibrahim HN (2011) Long-term outcomes of kidney donors. Curr Opin Nephrol Hypertens 20(6): 605-609.

7. Timmerman L, Laging M, Timman R, Zuidema WC, Beck DK, et al. (2016) The impact of the donors' and recipients' medical complications on living kidney donors' mental health. Transpl Int 29(5): 589-602.

8. Scandling JD. All's well following living kidney donation? Transpl Int 30(10): 972-974.

9. Maple H, Chilcot J, Weinman J, Mamode N (2017) Psychosocial wellbeing after living kidney donation - a longitudinal, prospective study. Transpl Int 30(10): 987-1001.

10. Jacobs CL, Gross CR, Messersmith EE, Hong BA, Gillespie BW, et al. (2015) Emotional and Financial Experiences of Kidney Donors over the Past 50 Years: The RELIVE Study. Clin J Am Soc Nephrol 10(12): 2221-2231.

11. Minz M, Udgiri N, Sharma A, Heer MK, Kashyap R, et al. (2005) Prospective psychosocial evaluation of related kidney donors: Indian perspective. Transplant Proc 37(5): 2001-2003.

12. Giessing M, Reuter S, Schönberger B, Deger S, Tuerk I, et al. (2004) Quality of life of living kidney donors in Germany: a survey with the Validated Short Form-36 and Giessen Subjective Complaints List-24 questionnaires. Transplantation 78(6): 864-872.
13. Keyes CL (2005) Mental illness and/or mental health? Investigating axioms of the complete state model of health. J Consult Clin Psychol 73(3): 539-548.

14. Clemens KK, Thiessen-Philbrook H, Parikh CR, Yang RC, Karley ML, et al. (2006) Donor Nephrectomy Outcomes Research (DONOR) Network. Psychosocial health of living kidney donors: a systematic review. Am J Transplant 6(12): 2965-2977.

15. Sharp J, McRae A, McNeill Y (2010) Decision making and psychosocial outcomes among living kidney donors: a pilot study. Prog Transplant 20(1):53-57.

16. Jordan J, Sann U, Janton A, Gossmann J, Kramer W, et al. (2004) Living kidney donors' long-term psychological status and health behavior after nephrectomy - a retrospective study. J Nephrol 17(5): 728-735.

17. Tong A, Chapman JR, Wong G, Kanellis J, McCarthy G, et al. (2012) The motivations and experiences of living kidney donors: a thematic synthesis. Am J Kidney Dis 60(1): 15-26.

18. Lagou DA, Ackoundou-N'guessan KC, Njapom TL, Sekongo YM, Guei CM, et al. (2016) Characteristics and outcome of living kidney donors after donation: A report from Cote d'Ivoire. Saudi J Kidney Dis Transpl 27(3): 563-568.

19. Fehrman-Ekholm I, Dunér F, Brink B, Tydén G, Elinder CG (2001) No evidence of accelerated loss of kidney function in living kidney donors: results from a cross-sectional follow-up. Transplantation 72(3): 444449.

20. Najarian JS, Chavers BM, McHugh LE, Matas AJ (1992) 20 years or more of follow-up of living kidney donors. Lancet 340(8823): 807-810.

21. Ibrahim HN, Foley R, Tan L, Rogers T, Bailey RF, et al. (2009) Long-Term Consequences of Kidney Donation N Engl J Med 360: 459-469.

22. Mjoen G, Hallan S, Hartmann A, Foss A, Midtvedt K, et al. (2014) Longterm risks for kidney donors. Kidney Int 86(1): 162-167.

23. Sahay M, Narayen G, Anuradha (2007) Risk of live kidney donation Indian perspective. J Assoc Physicians India 55: 267-70.

24. Benzing C, Hau HM, Kurtz G, Schmelzle M, Tautenhahn HM, et al. (2015) Long-term health-related quality of life of living kidney donors: a single-center experience. Qual Life Res 24(12): 2833-2842.

25. Muehrer RJ, Becker BN (2005) Life after transplantation: new transitions in quality of life and psychological distress. Semin Dial 18(2): 124-131.

26. Kennedy C, Ryan SA, Kane T, Costello RW, Conlon PJ (2017) The impact of change of renal replacement therapy modality on sleep quality in patients with end-stage renal disease: a systematic review and metaanalysis. J Nephrol 31(1): 61-70.

27. Muehrer RJ (2009) Sexuality, an important component of the quality of life of the kidney transplant recipient. Transplant Rev (Orlando) 23(4): 214-223.

28. Panuccio V, Tripepi R, Bellantoni M, Saporito L, Quattrone S, et al. (2017) Pruritus and quality of life in renal transplant patients. Clin Transplant 31(3).

29. Baek HS, Park KS, Ha IS, Kang HG, Cheong HI, et al. (2017) The impact of end-stage renal disease in children on their parents. Nephrology (Carlton).

30. Garcia MF, Andrade LG, Carvalho MF (2013) Living kidney donors - a prospective study of quality of life before and after kidney donation. Clin Transplant 27(1): 9-14

31. Zigmond AS, Snaith RP (1983) The hospital anxiety and depression scale. Acta Psychiatr Scand 67(6): 361-370. 

$\begin{array}{ll}\text { (C) } & \begin{array}{l}\text { This work is licensed under Creative } \\ \text { Commons Attribution 4.0 License } \\ \text { DOI: 10.19080/JOJUN.2018.05.555667 }\end{array}\end{array}$
Your next submission with Juniper Publishers will reach you the below assets

- Quality Editorial service

- Swift Peer Review

- Reprints availability

- E-prints Service

- Manuscript Podcast for convenient understanding

- Global attainment for your research

- Manuscript accessibility in different formats

( Pdf, E-pub, Full Text, Audio)

- Unceasing customer service

Track the below URL for one-step submission https://juniperpublishers.com/online-submission.php 